\title{
ENHANCED ACTIVITY OF TIO 2 /NATURAL ZEOLITE COMPOSITE FOR DEGRADATION OF METHYL ORANGE UNDER VISIBLE LIGHT IRRADIATION
}

\author{
Arif Rahman ${ }^{1 *}$, Muktiningsih Nurjayadi ${ }^{1}$, Rika Wartilah ${ }^{1}$, Eny Kusrini ${ }^{2}$, \\ Eko Adi Prasetyanto ${ }^{3}$, Volkan Degermenci ${ }^{4}$ \\ ${ }^{1}$ Department of Chemistry, Faculty of Mathematics \& Natural Sciences, Universitas Negeri Jakarta, \\ Rawamangun 13220, Indonesia \\ ${ }^{2}$ Department of Chemical Engineering, Faculty of Engineering, Universitas Indonesia, Kampus UI \\ Depok, Depok 16424, Indonesia \\ ${ }^{3}$ Faculty of Medicine and Health Sciences, Universitas Katolik Indonesia Atma Jaya, Jl. Pluit Raya \\ 2, Jakarta 14440, Indonesia \\ ${ }^{4}$ School of Engineering, University of Warwick, Coventry, CV4 7AL, United Kingdom
}

(Received: August 2018 / Revised: September 2018 / Accepted: October 2018)

\begin{abstract}
A series of titanium dioxide nanoparticles anchored on mordenite zeolite from an Indonesian natural deposit were prepared by the sol-gel route using a titanium isopropoxide sol as the precursor. Mordenite was incorporated during the sol-gel process by dispersing mordenite powder into the titania sol-gel precursor. The resulting titanium dioxide nanoparticles were in the anatase and rutile form, as confirmed by X-Ray diffraction (XRD) spectroscopy. Diffuse reflectance ultra violet visible (DR-UVVis) spectroscopy analysis indicated a red shift for the band gap energy, which enabled the materials to absorb ultraviolet to visible light. Subjecting the material to photodegradation in a reactor under ultraviolet and visible radiation gave better dye degradation under visible light than ultraviolet irradiation and the yield was proportional with the content of $\mathrm{TiO}_{2}$ nanoparticles incorporated into the zeolite.
\end{abstract}

Keywords: Natural zeolite; Photocatalysis; $\mathrm{TiO}_{2}$ photocatalyst

\section{INTRODUCTION}

The various applications of photocatalysis based on titanium dioxide is driving rapid growth in this research (Alvarez et al., 2018). One of the prominent applications in this field is the decomposition of organic pollutants. The photocatalytic activity of $\mathrm{TiO}_{2}$ for organic pollutant decomposition is mainly influenced by the crystallinity, particle size, crystal phase, and surface area of the $\mathrm{TiO}_{2}$. A study conducted by Yener et al. (2017) revealed that the anatase form of $\mathrm{TiO}_{2}$, which has a small particle size and high crystallinity, is needed to obtain high photocatalytic activity. However, the presence of a certain amount of $\mathrm{TiO}_{2}$ in the rutile phase can increase photocatalytic activity. This is related to the creation of holes and electrons on the surface of $\mathrm{TiO}_{2}$ for reaction with the substrate and the lifetime of these holes and electrons (Sun et al., 2015).

Many synthesis methods have been developed to obtain $\mathrm{TiO}_{2}$ nanoparticles, such as aerosol pyrolysis, amorphous $\mathrm{TiO}_{2}$ calcination, and colloidal surfactant synthesis (Sun et al., 2015). In general, these methods have the disadvantage of generating products that do not perform

\footnotetext{
${ }^{*}$ Corresponding author's email: arifrahman@unj.ac.id, Tel. +62-21-4898486, Fax. +62-21-4898486
}

Permalink/DOI: https://doi.org/10.14716/ijtech.v9i6.2368 
sufficiently for photocatalytic applications. However, several methods of synthesis of $\mathrm{TiO}_{2}$ nanoparticles, such as hydrothermal, solvothermal, and microwave methods, can produce $\mathrm{TiO}_{2}$ nanoparticles with high crystallinity and controlled size. Nevertheless, these methods are relatively complicated and require high temperatures and pressures. All three methods require the conversion of the precursors into colloidal forms through the sol-gel process and special equipment to facilitate the $\mathrm{TiO}_{2}$ crystal formation.

In the sol-gel process, metal alkoxides are hydrolyzed by alcohol to metal hydroxide. The solgel method has been widely used for the synthesis of oxide materials or other materials, such as $\mathrm{SiO}_{2}$ and $\mathrm{PbI}_{2}$ (Lalena \& Cleary, 2005). Using this method, anatase, rutile, and brookite $\mathrm{TiO}_{2}$ nanoparticles have been successfully synthesized (Zhang et al., 2014). Zhang et al. (2018) successfully made rutile and anatase $\mathrm{TiO}_{2}$ nanoparticles, whereas Yener et al. (2017) successfully produced $\mathrm{TiO}_{2}$ nanoparticles in the mordenite structure.

The use of porous material as a host to control the metal oxide particle size has been reported. $\mathrm{TiO}_{2}, \mathrm{CdO}$, and $\mathrm{ZnO}$ have been successfully synthesized by an ion exchange method using $\mathrm{NaY}$ zeolite as a host (Zhao et al., 1996). The use of clinoptilolite natural zeolites as host materials for biogas purification was reported by Kusrini et al. (2016). Efforts to utilize Indonesian natural zeolite for catalysis applications were made by Hidayat et al. (2018). The utilization of zeolite as a carrier in $\mathrm{TiO}_{2}$ synthesis results in smaller particle sizes of $\mathrm{TiO}_{2}$ than can be obtained with pure $\mathrm{TiO}_{2}$ (Hadjltaief et al., 2016), making this zeolite use more desirable in the synthesis of $\mathrm{TiO}_{2}$ nanoparticles. This is because the photocatalytic activity of the $\mathrm{TiO}_{2}$-zeolite system increases when compared to the $\mathrm{TiO}_{2}$ system (Chang et al., 2015).

Zeolite is a porous aluminosilicate material with a unique three-dimensional structure. It is widely used as a catalyst, adsorbent, and ion exchanger. Its pore structure also allows zeolite to be used as a host material. The utilization of zeolite is limited by the high cost of basic materials in industrial scale applications (Maraschi et al., 2014)

In this report, we incorporate $\mathrm{TiO}_{2}$ nanoparticles onto zeolite pores through sol-gel and impregnation processes to enhance the reactivity of the particles. We characterized the catalyst system and examined it for photocatalytic dye degradation under visible light than ultraviolet irradiation.

\section{METHODS}

\subsection{Materials}

Titanium (IV) isopropoxide 97\% (Aldrich), nitric acid 65\% (Merck), Methyl Orange (MO), and 2-propanol (Merck) were used directly without purification. Demineralized water (aqua DM) was used as the solvent. Mordenite type natural zeolite (150 mesh) was obtained from Lampung, Indonesia.

\subsection{Synthesis $\mathrm{TiO}_{2}$ Sol-gel}

The $\mathrm{TiO}_{2}$ sol solution was made from titanium (IV) isopropoxide. A total of $67.5 \mathrm{~mL}$ of titanium (IV) isopropoxide and $16 \mathrm{~mL}$ of 2-propanol were combined in a $100 \mathrm{~mL}$ beaker. The resulting solution was added slowly to $223.5 \mathrm{~mL}$ of demineralized water in a $500 \mathrm{~mL}$ beaker, with constant stirring using a magnetic stirrer. The solution was homogenized with stirring for 10 minutes and then added slowly to $3 \mathrm{~mL}$ of $65 \% \mathrm{HNO}_{3}$. This mixture was then heated to $80^{\circ} \mathrm{C}$ for 8 hours with constant stirring. A white $\mathrm{TiO}_{2}$ solution was produced and was used to make zeolite- $\mathrm{TiO}_{2}$.

\subsection{Synthesis of $\mathrm{TiO}_{2} / \mathrm{Natural}$ Zeolite}

The desired amounts of natural zeolites were dispersed in water and then slowly added to a solgel solution of $\mathrm{TiO}_{2}$ with constant stirring. Stirring was continued for 2 hours to generate 
homogeneous $\mathrm{TiO}_{2} /$ zeolite preparations with a concentration of $2.5 \%, 5 \%$, and $10 \%$. The $\mathrm{TiO}_{2} /$ zeolite obtained was then dried at $100^{\circ} \mathrm{C}$ for 4 hours. Some samples were calcined at $500^{\circ} \mathrm{C}$ for 6 hours. Dried and calcined samples were characterized by fourier-transform infrared spectroscopy (FTIR), specific surface area (SSA), XRD, and DR-UVVis techniques. The quantitative analyses were done on a Biospec 1601V (Shimadzu) spectrophotometer, FTIR instrument (Perkin Elmer), DR UV-Vis Spectroscopy instrument (Pharmaspec UV 1700 UVVIS Spectrophotometer with a Specular Reflectance Attachment), and an XRD instrument (Shimadzu X-Ray Diffractometer 7000).

\subsection{Photocatalysis Experiments}

A total of 1 gram of sample was dispersed in $200 \mathrm{ml}$ of demineralized water, and then homogenized by constant stirring using a magnetic stirrer. A $60 \mathrm{~mL}$ volume of $30 \mathrm{ppm} \mathrm{MO}$ solution was then added to the sample. The decomposition rate of MO was observed by removing $10 \mathrm{~mL}$ of the mixture every 30 minutes for 5 hours and measuring the absorption with the spectrophotometer at maximum wavelength of $464 \mathrm{~nm}$. The experiments to evaluate photocatalysis performance were carried out in the dark, in natural sunlight, and under UV lights.

\section{RESULTS AND DISCUSSION}

\section{1. $\mathrm{TiO}_{2} /$ Natural Zeolite Characterization}

The loading of low concentrations $\mathrm{TiO}_{2}$ into zeolites produced relatively small amounts of $\mathrm{TiO}_{2}$, this was confirmed by atomic absorbance spectroscopy. Loading of titanium dioxide onto natural zeolites does not damage the structure of the zeolites, although high loading of $\mathrm{TiO}_{2}$ onto zeolites will usually cause some damage to the zeolite structure ( $\mathrm{Li}$ et al., 2005). We observed the interaction of titanium dioxide on zeolite by FTIR spectroscopy and examined the effect of the loaded $\mathrm{TiO}_{2}$ on the zeolite structure, the $\mathrm{TiO}_{2}$ phase, and the effect of the concentration of the precursor. The samples were analyzed by X-ray diffraction.

Table 1 Effect of precursor concentrations on loaded $\mathrm{TiO}_{2}$ into natural zeolite

\begin{tabular}{|c|c|c|}
\hline Samples & $\begin{array}{l}\text { Concentration of } \mathrm{TiO}_{2} \text { in } \\
\text { precursor solutions }(\% \mathrm{~m} / \mathrm{m})\end{array}$ & $\begin{array}{l}\mathrm{TiO}_{2} \text { loaded onto zeolites } \\
\text { samples ( } \% \text { mass })\end{array}$ \\
\hline Zeolite & - & 0.26 \\
\hline Zeolite- $\mathrm{TiO}_{2} 2.5 \%$ & 2.5 & 9.5 \\
\hline Zeolite- $\mathrm{TiO}_{2} 5 \%$ & 5 & 18.1 \\
\hline Zeolite- $\mathrm{TiO}_{2} 10 \%$ & 10 & 28.6 \\
\hline
\end{tabular}

The presence of a pore system in the zeolite structure increased the amount of $\mathrm{TiO}_{2}$ loaded onto the zeolite. The interaction between $\mathrm{TiO}_{2}$ and zeolite can be observed by investigating the transmission spectra of FTIR for zeolite and $\mathrm{TiO}_{2}$-zeolite. The FTIR zeolite spectra have peaks in the regions of $3622,3640,1634,1051,790,607,523$, and $467 \mathrm{~cm}^{-1}$. The typical peaks for zeolites are 1051 and $467 \mathrm{~cm}^{-1}$ for the zeolite internal tetrahedral system, as well as 790, 607, and $523 \mathrm{~cm}^{-1}$ for the zeolite external system. The peaks at 3622,3640 , and $1634 \mathrm{~cm}^{-1}$ are the peaks that show the $-\mathrm{OH}$ stretch vibration.

The most common peak is in the area of $950-1250 \mathrm{~cm}^{-1}$ and $420-500 \mathrm{~cm}^{-1}$. The area of $950-$ $1250 \mathrm{~cm}^{-1}$ shows the asymmetric stretch vibration of T-O-T (T; $\mathrm{Al}$ or $\mathrm{Si}$ ) in the double ring and pore interactions in the zeolite external system, whereas the area of $420-500 \mathrm{~cm}^{-1}$ is the internal tetrahedral system (Lechert, 1984). 
The FTIR spectra of the $2.5 \%$ Zeolite- $\mathrm{TiO}_{2}$ samples were similar to the zeolite spectra but had new peaks at 2426 and $1384 \mathrm{~cm}^{-1}$. The new peaks show the bond between $\mathrm{C}-\mathrm{H}$ and $\mathrm{C}-\mathrm{O}$ from the alkoxide compounds that were used as precursors. As well as these new peaks, we also observed peak widening and shifting. The widening and shifting peak at $1055 \mathrm{~cm}^{-1}$ occurs due to the presence of $\mathrm{TiO}_{2}$ attached to the zeolite (Chen et al., 1999). Peak shifts also occurred from the $790 \mathrm{~cm}^{-1}$ area in the zeolite to $789 \mathrm{~cm}^{-1}$. We found a change in the shape of the shoulder at an area of $600-700 \mathrm{~cm}^{-1}$. A change in the shape of the spectrum in the region of $600-790 \mathrm{~cm}^{-1}$ indicates the interaction of $\mathrm{TiO}_{2}$ with the zeolite external pore system. The interaction of $\mathrm{TiO}_{2}$ with the zeolite system occurs in the formation of Ti-O-Si and / or Ti-O-Al bonds, as reported by Li et al. (2005).

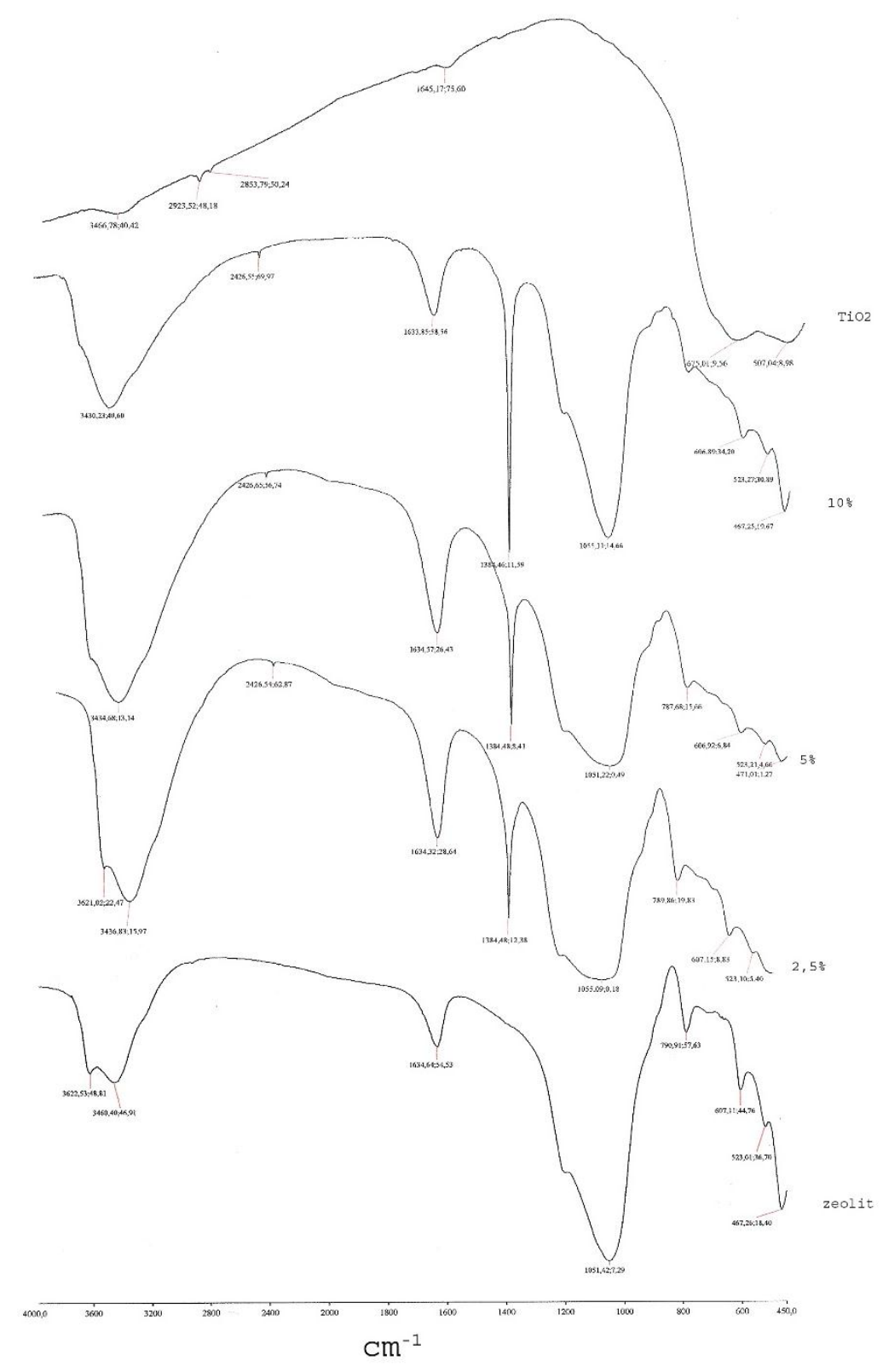

Figure 1 FTIR spectra of $\mathrm{TiO}_{2}$ loaded onto a natural zeolite structure via the sol-gel route

The diffraction pattern of $\mathrm{TiO}_{2}$-zeolite samples in Figure 2 shows that the $\mathrm{TiO}_{2}$ precursor does not damage the zeolite structure. This can be observed from the presence of a typical peak for mordenite at $2 \theta=22^{\circ}$ and this peak does not decrease in intensity over various concentrations 
of $\mathrm{TiO}_{2}$ precursor. The XRD patterns also exhibit $\mathrm{TiO}_{2}$ crystalline phases in the anatase and rutile form. The typical peak is in the area of $2 \theta=25^{\circ}$ for anatase, and $2 \theta=28^{\circ}$ for rutile. The XRD pattern reveals that each loading concentration has both anatase and rutile $\mathrm{TiO}_{2}$ phases. The intensity of both the anatase and rutile peaks increases with increasing $\mathrm{TiO}_{2}$ concentration.

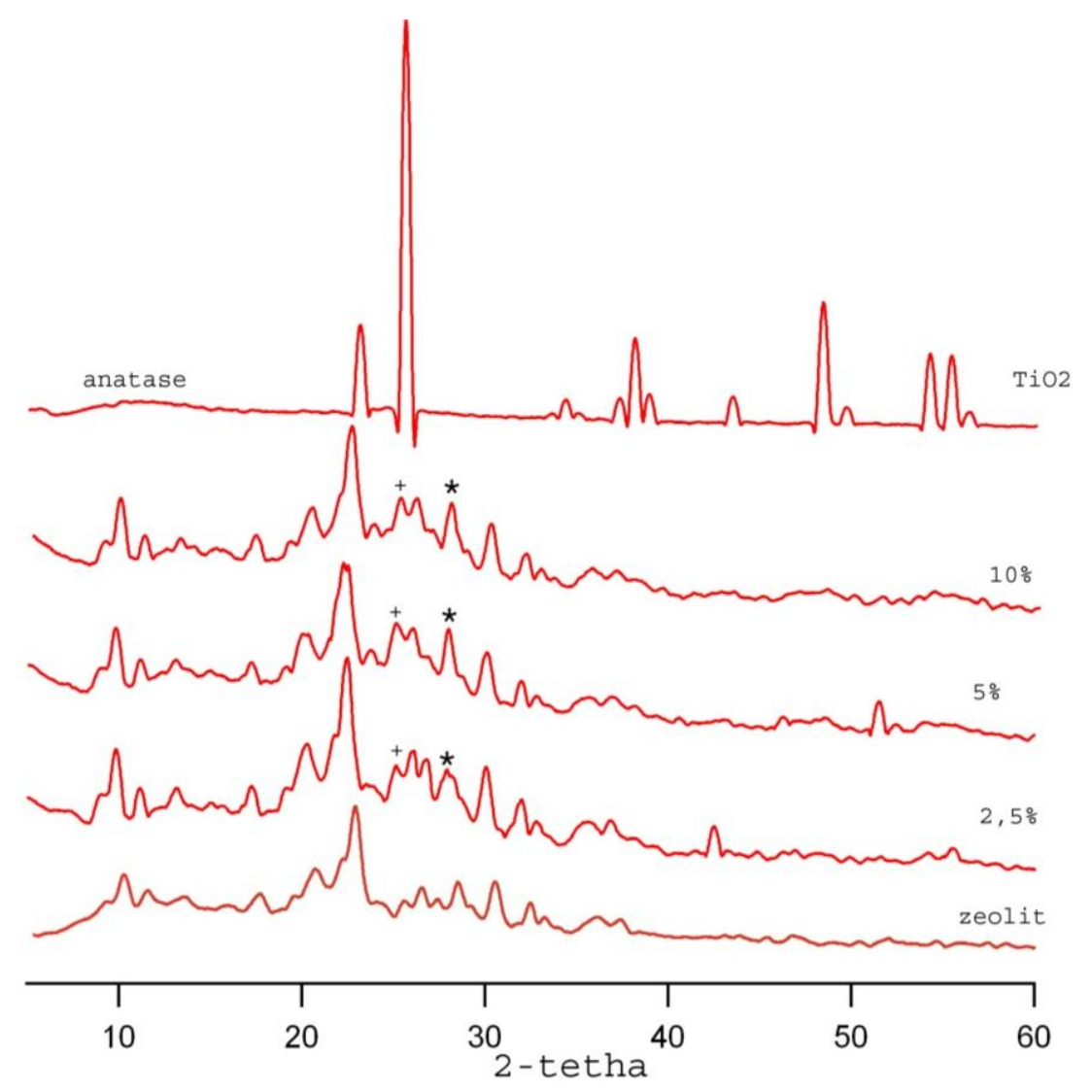

Figure $2 \mathrm{X}$-ray diffractogram from loaded $\mathrm{TiO}_{2}$ into natural zeolite $\left({ }^{+}\right.$: anatase $\mathrm{TiO}_{2}$, *: rutile $\left.\mathrm{TiO}_{2}\right)$

Band gap energy measurements were carried out by DR UV-Vis spectroscopy analysis. The aim of band gap energy measurement is to determine whether a shift has occurred in the edge absorption to a smaller wavelength. This would occur as a result of the reduced size of the $\mathrm{TiO}_{2}$ particles and is referred to as the quantum size effect (Zhao et al., 1996).

Table 2 Band gap energy of composite $\mathrm{TiO}_{2} /$ natural zeolite

\begin{tabular}{lcc}
\hline \multicolumn{1}{c}{ Sample } & $\lambda(\mathrm{nm})$ & $\mathrm{Eg}(\mathrm{eV})$ \\
\hline $\mathrm{TiO}_{2}$ & 404 & 3.07 \\
Zeolite- $\mathrm{TiO}_{2} 2.50 \%$ & 360 & 3.44 \\
Zeolite- $\mathrm{TiO}_{2}$ 5\% & 368 & 3.37 \\
Zeolite- $\mathrm{TiO}_{2} 10 \%$ & 375 & 3.30 \\
\hline
\end{tabular}

Figure 3 shows a shift in the absorption edge of the Zeolite- $\mathrm{TiO}_{2}$ sample towards a shorter wavelength (blue shift) when compared to the $\mathrm{TiO}_{2}$ bulk uptake. A shift in edge absorption also occurs, indicating the widening of the valence band and conductance bands. This widening of these bands occurs because of the reduction in particle size, again indicating the quantum size effect, as stated by Hoffmann et al. (1995). 
Figure 3 shows the maximum peak in the area 360-375. In addition to the maximum peak, peaks are also evident at longer wavelengths. These peaks show the hydroxide species of Ti. The peaks are formed to a greater extent as the concentration of the sol-gel precursor increases. Thus, the Ti hydroxide species are formed to a greater extent by increasing the concentration of the sol-gel precursor.

Because of the difference in size between the bulk $\mathrm{TiO}_{2}$ and the $\mathrm{TiO}_{2}$ produced, the size of the Eg for both $\mathrm{TiO}_{2}$ forms is also quite different. This difference in Eg values occurs because of the quantum size effect or QSE, where a smaller sized material will have a greater Eg value (Linsebigler et al., 1995). This is due to the increasing distance between the valence band and the conductance band in the smaller material. The Eg values can be determined from the results of spectroscopic analysis by DR UV-Vis.

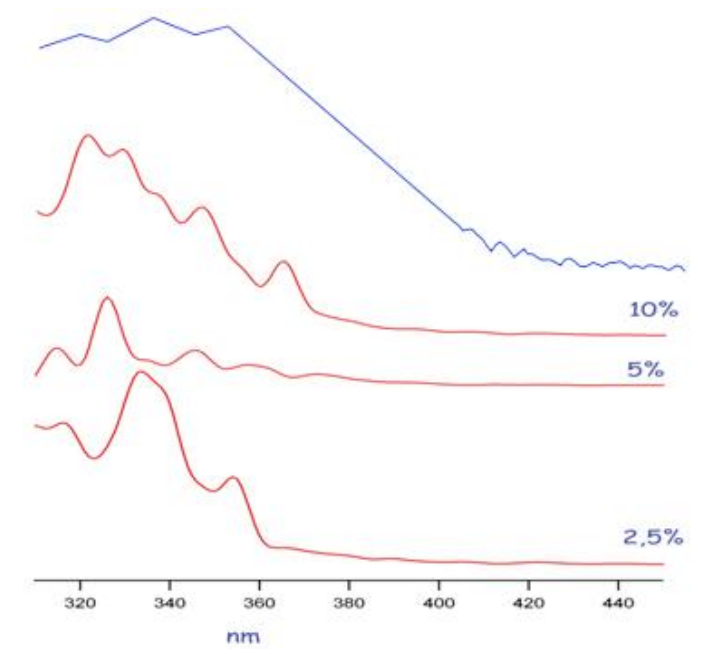

Figure 3 Diffuse reflectance spectroscopy spectra of composite $\mathrm{TiO}_{2} /$ natural zeolite

\subsection{Photocatalysis Performance}

The effect of the amount of $\mathrm{TiO}_{2}$ on photocatalysts has been reported by Chatti et al. (2007). In that report, an increase in MO reduction was observed both with visible light and sunlight by increasing the amount of $\mathrm{TiO}_{2}$ in the photocatalysts from $5 \%$ to $10 \%$. The presence of light and the light sources themselves affect the photocatalytic process. The results from the present study confirmed that the photocatalysis process does not occur in the dark. This is because, in the dark condition, recombination occurs between the holes $+(\mathrm{h}+)$ and electrons $(\mathrm{e}-)$ that form when the excitation occurs. This recombination can occur inside the particle or on the surface of the particle. The occurrence of this recombination causes a reduction or even a loss of photocatalytic activity from the photocatalysts (Chatti et al., 2007). The difference in the light source used also affects the photocatalysis that occurs. In the present study, the photocatalysis process occurs with the use of UV light and sunlight as a light source. The photocatalysis process is better with sunlight as a light source than with UV light. This is because sunlight has greater energy when compared to UV light, so it causes more electron excitation to occur.

The influence of light sources on the photocatalysis process has been observed by several researchers. For example, Rashed and El-Amin (2007) reported that the MO degradation process is very good in the presence of sunlight when compared to the use of halogen lamps or fluorescent lamps as light sources. Kansal et al. (2007) reported that MO removal occurs faster in the presence of sunlight than in UV light. 


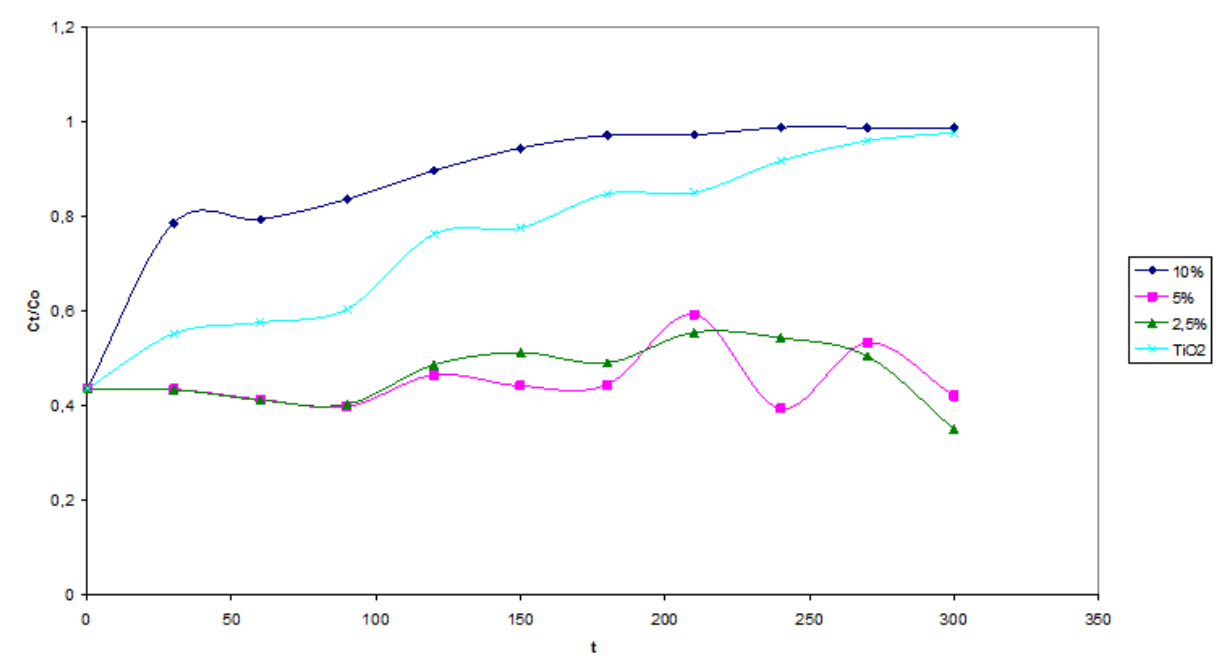

(a)

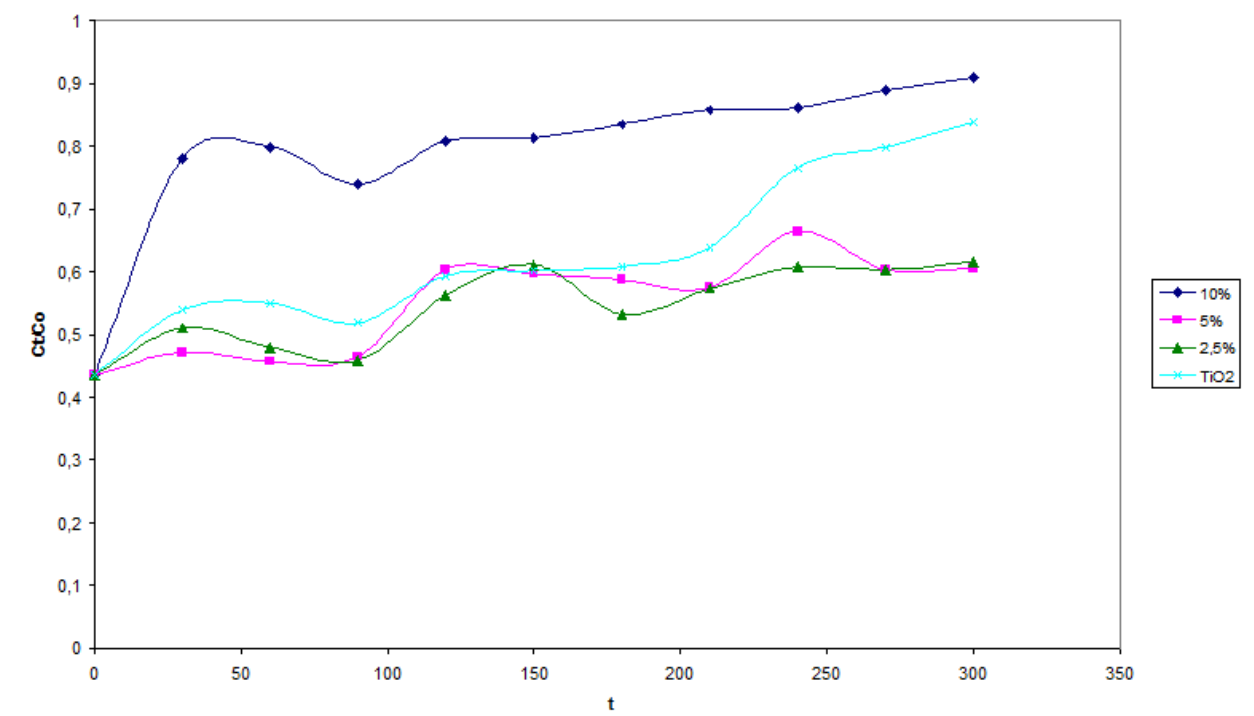

(b)

Figure 4 Photocatalytic performance under solar light (a) and under UV light (b)

The effect of the $\mathrm{TiO}_{2}$ system and $\mathrm{TiO}_{2}$-zeolite system on the photocatalysis process was also examined in this study. The results show that the MO degradation process occurs better with the $\mathrm{TiO}_{2}$-zeolite systems than with the $\mathrm{TiO}_{2}$ systems. This is because of the super adsorption ability of zeolites ( $\mathrm{Li}$ et al., 2005). In addition, the electron zeolite $\mathrm{TiO}_{2}$ system from the conductance band moves rapidly out of $\mathrm{TiO}_{2}$ particles before recombination occurs, because the surface of the electron-rich zeolite functions as an $\mathrm{h}+$ inhibitor. This is the reason why $\mathrm{TiO}_{2}$-zeolite systems have better photocatalytic activity than $\mathrm{TiO}_{2}$ systems (Anandan and Yoon, 2003). Zhang et al. (2018) and Sayilkan et al. (2007) reported photocatalytic activity on Rhodamine B for pure $\mathrm{SiO}_{2} / \mathrm{TiO}_{2}$ and $\mathrm{TiO}_{2}$ oxide mixtures. $\mathrm{The}_{\mathrm{SiO}_{2}} / \mathrm{TiO}_{2}$ had better photocatalytic activity than pure $\mathrm{TiO}_{2}$ because the addition of a number of $\mathrm{SiO}_{2}$ molecules to $\mathrm{TiO}_{2}$ will increase the thermal stability, the surface area, and the surface acidity, which then influence the addition of active sites that support the occurrence of photocatalytic processes.

\section{CONCLUSION}

Taken together, the results of this study indicate that $\mathrm{TiO}_{2}$ nanoparticles synthesized using the impregnated sol-gel method in natural zeolites have a smaller size than the bulk $\mathrm{TiO}_{2}$, which is 
in the nanometer range. The interaction of $\mathrm{TiO}_{2}$ with zeolite occurs on the external surface of the zeolites, where the $\mathrm{TiO}_{2}$ crystalline phase is a mixture of anatase and rutile. The $\mathrm{TiO}_{2}-$ zeolite produced has photocatalytic activity. The photocatalytic activity increases with increasing concentration of the titanium dioxide precursor.

\section{REFERENCES}

Alvarez, K.M., Alvarado J., Soto, B.S., Hernandez, M.A., 2018. Synthesis of $\mathrm{TiO}_{2}$ Nanoparticles and $\mathrm{TiO}_{2}$-Zeolite Composites and Study of Optical Properties and Structural Characterization. Optik, Volume 169, pp. 137-146

Chatti, R., Rayalu, S.S., Dubey, N., Labhsetwar, N., Devotta, S., 2007. Solar-based Photoreduction of Methyl Orange using Zeolite Supported Photocatalytic Materials. Solar Energy Materials and Solar Cells, Volume 91(2), pp. 180-190

Chang, C.-T., Wang, J.-J.. Ouyang, T., Zhang, Q., Jing., Y.-H., 2015. Photocatalytic Degradation of Acetaminophen in Aqueous Solutions by $\mathrm{TiO}_{2} / \mathrm{ZSM}-5$ Zeolite with Low Energy Irradiation. Materials Science \& Engineering B, Volume 196, pp. 53-60

Chen, H., Matsumoto, A., Nishimiya, N., \& Tsutsumi, K. (1999). Preparation and characterization of $\mathrm{TiO}_{2}$ incorporated Y-zeolite. Colloids and Surfaces A: Physicochemical and Engineering Aspects, 157(1-3), 295-305. doi:10.1016/s0927-7757(99)00052-7

Hadjltaief, H.B, Zina, M., Galvez, M., Da Costa, P., 2016. Photocatalytic Degradation of Methyl Green Dye in Aqueous Solution over Natural Clay-supported $\mathrm{ZnO}-\mathrm{TiO}_{2}$ Catalysts. Journal of Photochemistry and Photobiology A: Chemistry, Volume 315, pp. 25-33

Hidayat, A., Mukti, N.I.F., Handoko, B., Sutrisno, B., 2018. Biodiesel Production from Rice Bran Oil over Modified Natural Zeolite Catalyst. International Journal of Technology, Volume 9(2), pp. 400-411

Hoffmann, M.R., Martin, S.T., Choi, W., Bahnemann, D.W., 1995. Environmental Aplications of Semiconductor Photocatalysis, Chemical Reviews, Volume 95(1), 69-96

Kansal, S., Singh, M., Sud, D., 2007. Studies on Photodegradation of Two Commercial Dyes in Aqueous Phase using Different Photocatalysts. Journal of Hazardous Materials, Volume 141(3), pp. 581-590

Kusrini, E., Lukita, M., Gozan, M., Susanto, B.H., Widodo, T.W., Nasution, D.A., Wu, S., Rahman, A., Siregar, Y.D.I., 2016. Biogas from Palm Oil Mill Effluent: Characterization and Removal of $\mathrm{CO}_{2}$ using Modified Clinoptilolite Zeolites in a Fixed-bed Column. International Journal of Technology. Volume 7(4), pp. 625-634

Lalena, J. N., Cleary, D.A., 2005. Principles of Inorganic Material Design. John Wiley \& Sons, Inc., USA

Lechert, 1984. The Physical Characterization of Zeolites. In: Ramôa, Ribeiro, F.R., Rodrigues, A.E., Rollmann, L.D, Naccache, C. (eds.). Zeolites: Science and Technology. Springer, Netherlands, pp. 163-164

Li, F.-F., Jiang, Y.-S., Yu, L.-X., Yang, Z.-W., Hou, T.-Y., Sun, S.-M., 2005. Surface Effect of Natural Zeolite (Clinoptilolite) on the Photocatalytic Activity of $\mathrm{TiO}_{2}$. Applied Surface Science, Volume 252(5), pp. 1410-1416

Linsebigler, A.L., Lu, G., Yates, T., 1995. Photocatalysis on $\mathrm{TiO}_{2}$ Surface: Principles, Mechanisms, and Selected Results. Chemical Reviews, Volume 95(3), pp. 735-758

Maraschi, F., Sturini, M., Speltini, A., Pretali, L., Profumo, A., Pastorello, A., Kumar, V., Ferretti, M., Caratto, V., 2014. TiO ${ }_{2}$-modified Zeolites for Fluoroquinolones Removal from Wastewaters and Reuse after Solar Light Regeneration. Journal of Environmental \& Chemical Engineering, Volume 2(4), pp. 2170-2176 
Rashed, M.N., El-Amin, A.A., 2007. Photocatalytic Degradation of Methyl Orange in Aqueous $\mathrm{TiO}_{2}$ under Different Solar Irradiation Source. International Journal of Physical Sciences, Volume 2, pp. 73-81

Sayilkan, F., Asilturk, M., Sener, S., Erdemoglu, S., Erdemoglu, M., Sayilkan, H., 2007. Hydrothermal Synthesis, Characterization and Photocatalytic Activity of Nanosized $\mathrm{TiO}_{2}$ Based Catalysts for Rhodamine B Degradation. Turkish Journal of Chemistry, Volume 31, pp. 211-221

Sun, Q., Hu, X.-L., Zheng, S.-L., Sun, Z.-M., Liu, S.-S., Li, H., 2015. Influence of Calcination Temperature on the Structural, Adsorption and Photocatalytic Properties of $\mathrm{TiO}_{2}$ Nanoparticles Supported on Natural Zeolite. Powder Technology, Volume 274, pp. 88-97

Yener, H.B., Yılmaz, M., Deliismail, Ö., Özkan, S.F., Helvacı Ş.Ş., 2017. Clinoptilolite Supported Rutile $\mathrm{TiO}_{2}$ Composites: Synthesis, Characterization, and Photocatalytic Activity on the Degradation of Terephthalic Acid. Separation and Purification Technology, Volume 173, pp. 17-26

Zhang, G.-G., Song, A.-K., Duan, Y.-W., Zheng, S.-L., 2018. Enhanced Photocatalytic Activity of $\mathrm{TiO}_{2} /$ Zeolite Composite for Abatement of Pollutants. Microporous and Mesoporous Materials, Volume 255, pp. 61-68

Zhang, J.., Zhou, P., Liu, J., Yu, J., 2014. New Understanding of the Difference of Photocatalytic Activity among Anatase, Rutile and Brookite $\mathrm{TiO}_{2}$. Physical Chemistry \& Chemical Physics, Volume 16(38), pp. 20382-20386

Zhao, X.S., Liu, G.Q., Millar, G.J., 1996. Encapsulation of Transition Metal Species into Zeolites and Molecular Sieves as Redox Catalysts: Part I-Preparation and Characterization of Nanosized $\mathrm{TiO}_{2}, \mathrm{CdO}$, and $\mathrm{ZnO}$ Semiconductor Particle Anchored in NaY Zeolite. Journal of Porous Materials, Volume 3, pp. 61-66 